$12-2014$

\title{
Substrate Concentration Influences Effective Radial Diffusion Coefficient in Canine Cortical Bone
}

\author{
Kurt Farrell \\ Cleveland State University \\ Daniel O'Conor \\ Cleveland State Unviersity \\ Mariela Gonzalez \\ Cleveland State University \\ Caroline Androjna \\ flfibelatffis linicadditional works at: https://engagedscholarship.csuohio.edu/encbe_facpub \\ rraded df Adidakamical Engineering Commons \\ Glevelabd Clinicess to this work benefit you? Let us know! \\ Publisher's Statement

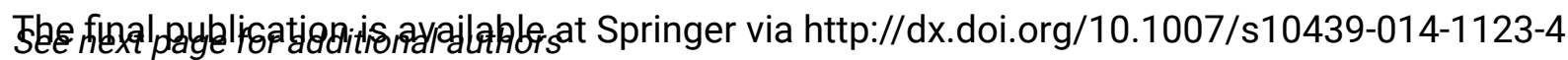

\section{Original Citation}

Farrell K, O'Conor D, Gonzalez M, Androjna C, Midura RJ, Tewari SN, Belovich J. Substrate Concentration Influences Effective Radial Diffusion Coefficient in Canine Cortical Bone. Ann Biomed Eng.

2014;42:2577-2588.

\section{Repository Citation}

Farrell, Kurt; O'Conor, Daniel; Gonzalez, Mariela; Androjna, Caroline; Midura, Ronald J.; Tewari, Surendra N.; and Belovich, Joanne M., "Substrate Concentration Influences Effective Radial Diffusion Coefficient in Canine Cortical Bone" (2014). Chemical \& Biomedical Engineering Faculty Publications. 143.

https://engagedscholarship.csuohio.edu/encbe_facpub/143

This Article is brought to you for free and open access by the Chemical \& Biomedical Engineering Department at EngagedScholarship@CSU. It has been accepted for inclusion in Chemical \& Biomedical Engineering Faculty Publications by an authorized administrator of EngagedScholarship@CSU. For more information, please contact library.es@csuohio.edu. 


\section{Authors}

Kurt Farrell, Daniel O'Conor, Mariela Gonzalez, Caroline Androjna, Ronald J. Midura, Surendra N. Tewari, and Joanne M. Belovich 


\title{
Substrate Concentration Influences Effective Radial Diffusion Coefficient in Canine Cortical Bone
}

\author{
Kurt Farrell, Daniel O’Conor, Mariela Gonzalez, Caroline Androjna, Ronald J. Midura, \\ Surendra N. Tewari, and Joanne Belovich
}

\begin{abstract}
Transport of nutrients and waste across osseous tissue is dependent on the dynamic micro and macrostructure of the tissue; however little quantitative data exists examining how this transport occurs across the entire tissue. Here we investigate in vitro radial diffusion across a section of canine tissue, at dimensions of several hundred microns to millimeters, specifically between several osteons connected through a porous microstructure of Volkmann's canals and canaliculi. The effective diffusion coefficient is measured by a "sample immersion" technique presented here, in which the tissue sample was immersed in solution for $18-30 \mathrm{~h}$, image analysis software was used to quantify the solute concentration profile in the tissue, and the data were fit to a mathematical model of diffusion in the tissue. Measurements of the effective diffusivity of sodium fluorescein using this technique were confirmed using a standard two-chamber diffusion system. As the solute concentration increased, the effective diffusivity decreased, ranging from $1.6 \times 10^{-7} \pm 3.2 \times$ $10^{-8} \mathrm{~cm}^{2} / \mathrm{s}$ at $0.3 \mu \mathrm{M}$ to $1.4 \times 10^{-8} \pm 1.9 \times 10^{-9} \mathrm{~cm}^{2} / \mathrm{s}$ at $300 \mu \mathrm{M}$. The results show that there is no significant difference in mean diffusivity obtained using the two measurement techniques on the same sample, $3.3 \times$ $10^{-8} \pm 3.3 \times 10^{-9} \mathrm{~cm}^{2} / \mathrm{s}$ (sample immersion), compared to $4.4 \times 10^{-8} \pm 1.1 \times 10^{-8} \mathrm{~cm}^{2} / \mathrm{s}$ (diffusion chamber).
\end{abstract}

\section{INTRODUCTION}

Molecular diffusion is an important method by which nutrients and wastes are exchanged within tissue and organs. Tissue porosity and permeability, including the geometry, orientation, interconnectivity, branching and surface chemistry of pores directly influence the rate of diffusion in nearly all biological tissues. ${ }^{37}$ Bone is a biocomposite that, in adult human, contains a mineral phase (hydroxyapatite) and an organic phase in a 2:1 ratio, respectively. The organic phase is composed of $62 \%$ type I collagen, $26 \%$ minor collagens and noncollagenous proteins, $6 \%$ lipids and $6 \%$ complex carbohydrates. ${ }^{8,26}$ Further, it is well documented that the chemical environment directly influences the process of bone formation, and subsequently affects the architecture and composition of the tissue and thus the mechanical performance. ${ }^{35}$

Nutrient and waste transport activities are essential for maintaining the viability of osteocytes, which act as key regulators of all physiological processes pertaining to bone remodeling and homeostatic function. ${ }^{9.30}$ Diffusion within bone is limited by cortical bone tissue's paucity of a significant porous structure. Cortical bone porosity has been reported within literature as being as low as $8 \%$ for young individuals and up to $28 \%$ for elderly individuals. ${ }^{33}$ Volkmann's canals, canaliculi, and reabsorption cavities comprise the primary pathways for radial transport within the cortical tissue of the long bone. ${ }^{14}$

The large disparity in previously reported diffusivities for sodium fluorescein (and similarly-sized molecules) within cortical bone tissue, in which diffusivity values range from $7 \times 10^{-10} \mathrm{~cm}^{2} / \mathrm{s}$ to $3 \times 10^{-6} \mathrm{~cm}^{2} / \mathrm{s}$, may arise from a variety of factors. ${ }^{17,19,24,34}$ When 
measurements are done at a micron scale, such as in the technique of fluorescence recovery after photobleaching (FRAP), transport rates vary significantly depending on the specific tissue region examined (e.g., the hydroxyapatite matrix ${ }^{24}$ or through a canaliculus ${ }^{19,34}$ ). Moreover, many measurements were done in rabbit, rat, and mouse tissue, which have significantly different structural arrangements of cortical bone from that of human tissue. $2,10,19,34$

When bone tissue is mechanically loaded, it has been shown that convective transport occurs along with diffusive transport of solutes in the radial direction. ${ }^{4}$ It has been suggested that cyclic loading of cortical bone temporarily deforms the internal architecture of the bone, providing a pressure gradient which induces fluid displacement within the dense tissue matrix. ${ }^{14,16,25}$ This hypothesis has been supported by qualitative experiments at the millimeter level in which the transport rates of tracer molecules were shown to be increased by mechanical loading in ex vivo studies of the sheep forelimb. ${ }^{15,16}$ Quantitative demonstration of this effect has been demonstrated at the micron level within the lacunar-canalicular system of mice. $^{28}$

A standard and well-recognized technique for measurement of solute diffusivity through membranes and tissue sections is through the use of a two-chamber diffusion system. ${ }^{3.7}$ This method provides effective diffusivities at the macro-scale within tissue, rather than through the micron-scale, as provided by FRAP techniques. However, the two-chamber diffusion system is not amenable to measurements in a mechanically-loaded state. Given these limitations, we devised a new "sample immersion" technique in which the effective diffusivity of a fluorescent marker can be measured in tissue samples at the millimeter-scale, and which, with simple modifications, can be used in a mechanically-loaded state. Results using the method in the unloaded state were validated against the conventional two-chamber diffusion system. Measurements were performed in the radial direction of cortical bone sections of the canine tibia, which has similar osteonal structure to the human tibia. ${ }^{2,10}$ Fluorescein disodium salt was selected as the model solute due to its chemical similarity to vitamin D, estrogen, and testosterone, all of which are bone-effective agents.

\section{MATERIALS AND METHODS}

\section{Tissue Source and Preparation}

Bone samples were harvested from a single sacrificed canine (approximately $30 \mathrm{~kg}$ body weight) under an IACUC approved protocol at the Cleveland Clinic's
Lerner Research Institute. Both tibia in their entirety were dissected from the rest of the animal and the bone marrow was flushed out of the diaphyseal medullary cavity with repeated phosphate buffer saline (PBS) washes. The tibia was stored in PBS with $0.05 \%$ sodium azide (Sigma) at $4{ }^{\circ} \mathrm{C}$ for up to 1 year. Before use, the bone was cleaned a second time. All remaining soft tissues on the periosteal surface were completely removed by manual rubbing with a sterile PBS-soaked gauze in conjunction with a final PBS rinse. The cleaned bone was cut transversely into five equal length sections (Fig. la) using a Labcut 1010 Low Speed Diamond Saw (EXTEC Corp). The blade of the saw was kept wet during cutting with a solution of PBS to avoid dehydration of the samples. The periosteal portion was removed from each bone section using the saw (Fig. 2a). The tibia sections were stored in PBS with $0.05 \%$ sodium azide (Sigma) at $4{ }^{\circ} \mathrm{C}$ for up to 12 months.

\section{Diffusion Chamber Method}

\section{Sample Preparation}

The endosteal bone tissue was cut from the three sides of the bone section, resulting in three rectangular polygons, each approximately $17 \mathrm{~mm} \times 10 \mathrm{~mm} \times$ $3 \mathrm{~mm}$ (Figs. 2b, 2c). A hard, circular plastic tube ( $25 \mathrm{~mm} \mathrm{OD}, 24 \mathrm{~mm} \mathrm{ID}, 25 \mathrm{~mm}$ long) was used to encapsulate the bone sample. One end of the plastic tube was sealed with masking tape and the rectangular polygon bone sample (described above) was placed with the endosteal face on the tape as centrally in the tube as possible (Fig. 2d). Next, an orthodontic resin (Dentsply) was used to cover all remaining exposed sides of the bone sample and to fill the plastic tube. The resin-enclosed sample was allowed to harden for $24 \mathrm{~h}$. The masking tape was then removed, and the endosteal surface of the bone sample was rubbed with a Kimwipe soaked with PBS to moisten the bone and remove masking tape residue. Using a low-speed diamond saw, a transverse slice was cut from the sample with approximate thickness of 470 microns (Fig. 2e). The actual thickness was measured using a caliper at five different points around the slice. The newly cut slice (Fig. 2f) was dabbed with a Kimwipe to remove excess PBS. Krazy Glue (Elmer) was then applied to the re$\sin$ /bone and resin/plastic interfaces on the endosteal side of the sample using a disposable orthodontic brush (Henry-Schein) to assure a complete seal at these interfaces. The surface area available for diffusion was measured via calipers and geometric calculations. The bone slice was then placed in a modified $25 \mathrm{~mm}$ filter holder (ADVANTEC) with the endosteal side facing the donor chamber. This filter holder was modified by 


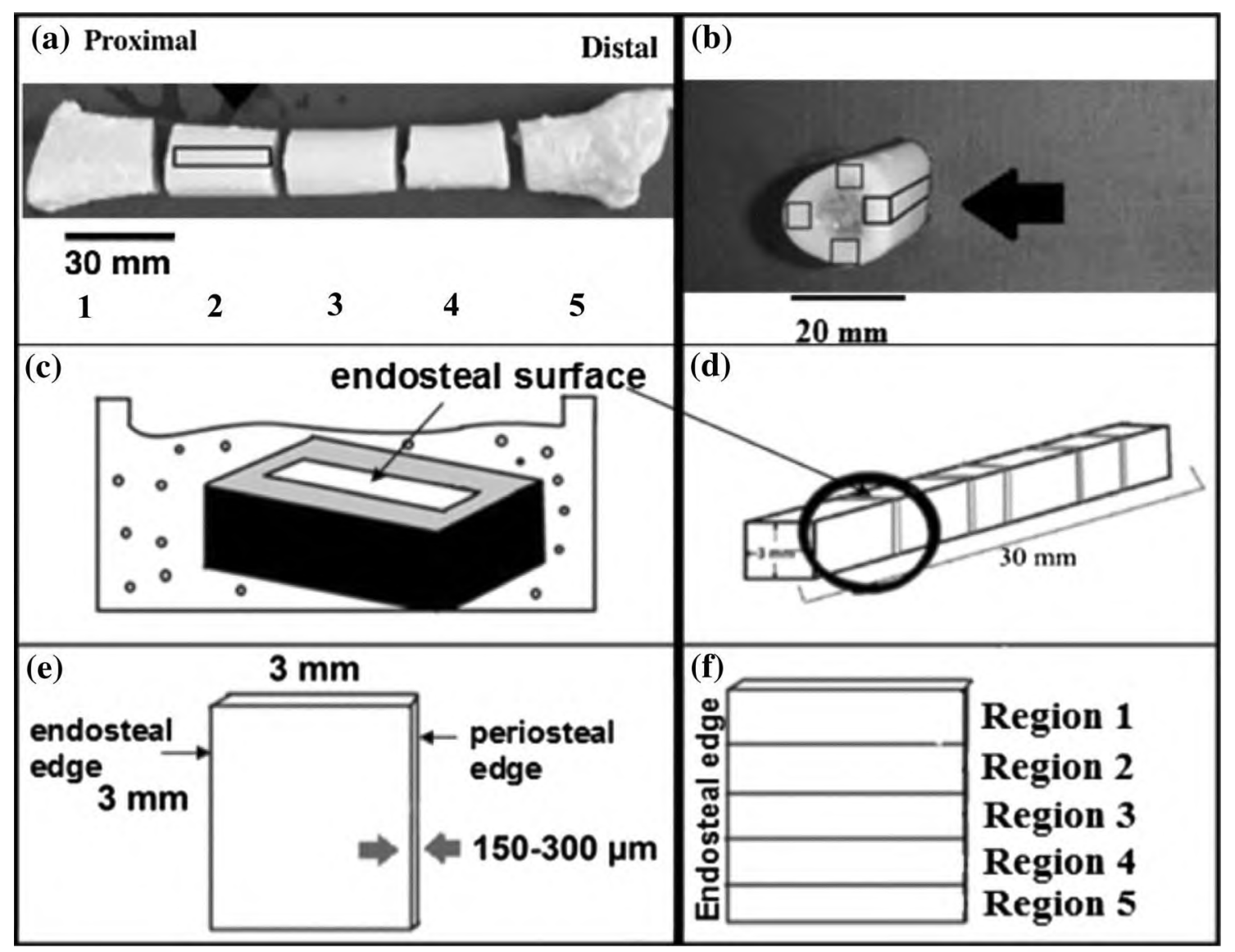

FIGURE 1. (a) Labeling of bone sections as seen from the raw bone sample harvested from the tibia of the canine; (b) beams cut from each section; (c) after the beam was embedded in resin, the endosteal side was exposed and embedded beam placed in a solution containing sodium fluorescein; $(d, e)$ thin slices were cut from two to six different positions within the beam (five slices shown here); (f) the image of the slice was divided into five equal regions, and the average intensity profile, as a function of distance, was calculated to yield a diffusivity value for each region.

fitting each end with a circular plastic piece designed to fit in the openings between the donor and receiver cells (Fig. 2g). The tube fitting external to each side of the filter holder was removed to increase access to the sample.

\section{Diffusion Experiment}

Diffusion trials were run in a two-chamber diffusion cell (Crown Glass) connected to a $37^{\circ} \mathrm{C}$ water bath (Fig. 3). The receiver chamber was filled with $50 \mathrm{~mL}$ of PBS and the donor chamber was filled with $50 \mathrm{~mL}$ of $0.3,30$, or $300 \mu \mathrm{M}$ fluorescein in PBS. Samples of $1 \mathrm{~mL}$ were taken once daily from the receiver chamber for 7-10 days and fluorescein concentration determined using an F-7000 Fluorescence Spectrophotometer (Hitachi). For repeated measurements of the same bone sample, the fluorescein solutions in both chambers were replaced with PBS. The solutions were agitated to rinse the chamber and bone sample and discarded, and the donor and receiver chambers filled with fresh solutions and the experiment repeated. A control experiment to evaluate device leakage was performed with a bone sample made impermeable with a complete coating of Krazy Glue and a $300 \mu \mathrm{M}$ fluorescein solution in the donor chamber. After 6 days, the fluorescein concentration in the receiver chamber was negligible $(<0.001 \%)$, indicating that there was no appreciable fluid leakage in this device.

\section{Data Analysis}

Assuming that the transport within the bone sample achieves quasi-steady state, the flux, $J_{\text {fluorescein }}$, applying Fick's Law, is given by:

$$
J_{\text {fluorescein }}=-D \frac{d C_{\text {bone }}}{d x}=\frac{D \Phi}{L}\left(C_{\mathrm{D}}-C_{\mathrm{R}}\right)
$$

where $C_{\text {bone }}, C_{\mathrm{D}}$, and $C_{\mathrm{R}}$ are the fluorescein concentrations in the bone, donor chamber, and receiver chamber, respectively; $L$ is the tissue thickness; and $\Phi$ is the partition coefficient. Mass balances in each of the diffusion cells are given by: 


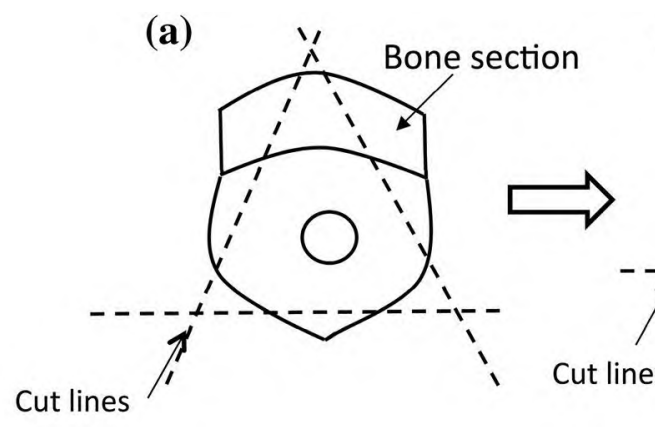

(b)

(d)

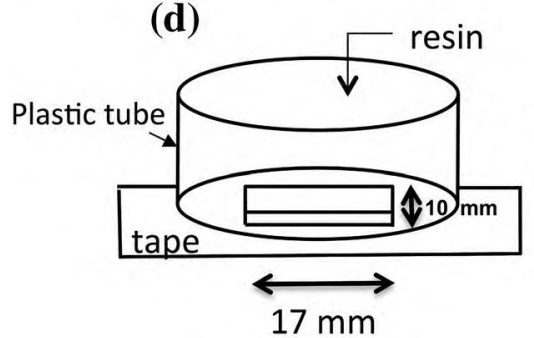

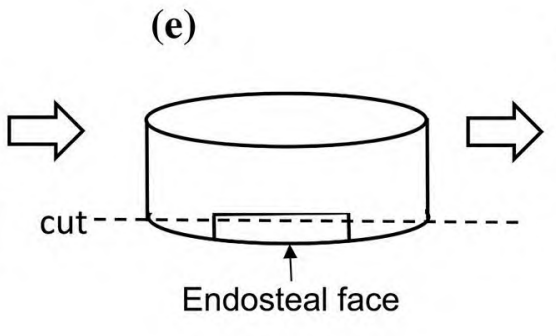

(c)

Bone samples

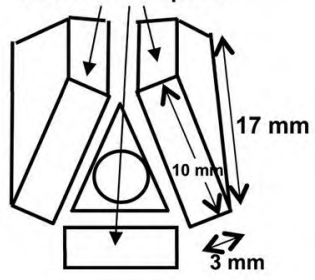

(f)

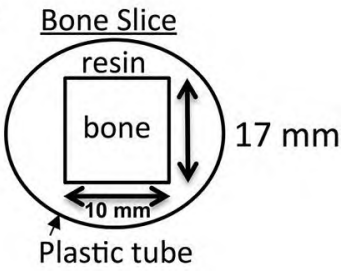

(g)

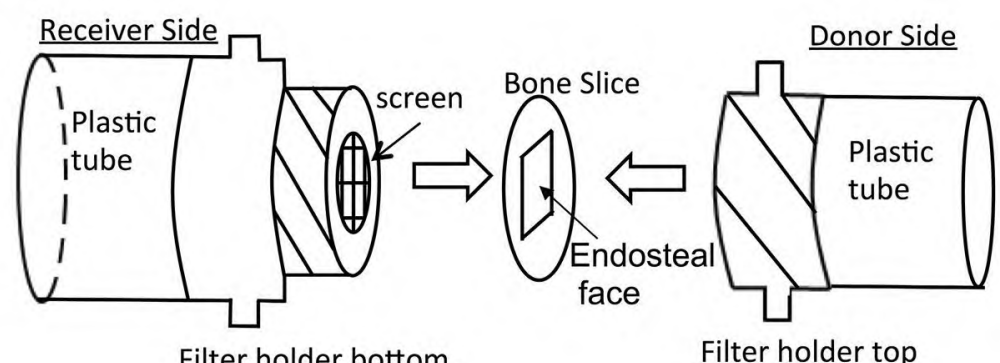

Filter holder bottom

Filter holder top

FIGURE 2. Sample preparation for use in the diffusion cell. (a)-(c) Arrangement of bone samples obtained from section of the tibia; (d) bone sample is placed on tape at center-bottom of plastic tube, and then surrounded with the dental resin; (e) after hardening and removal of the tape, the bottom surface is sliced off with the saw; (f) top view of bone sample, surrounded by resin and plastic tube; (g) Placement of sample in modified filter holder.

$$
\begin{array}{r}
-V \frac{d C_{\mathrm{D}}}{d t}=A J_{\text {fluorescein }}=V \frac{d C_{\mathrm{R}}}{d t} \\
C_{\mathrm{R}}=C_{\mathrm{o}}-C_{\mathrm{D}}
\end{array}
$$

where $V$ is the volume $(50 \mathrm{~mL})$ of both the donor and receiver chambers; $C_{0}$ is the initial concentration of fluorescein in the donor chamber; and $A$ is the surface area of the bone sample. Combining Eqs. (1) and (2), and integrating with initial conditions of $C_{\mathrm{D}}(0)=C_{0}$, $C_{\mathrm{R}}(0)=0$, yields ${ }^{7}$ :

$$
\ln \left(\frac{C_{\mathrm{o}}-2 C_{\mathrm{R}}}{C_{\mathrm{o}}}\right)=-\left(\frac{2 A D}{V L}\right) t
$$

$D$ was calculated from the slope of $\ln \left[\left(C_{\mathrm{o}}-2 C_{\mathrm{R}}\right)\right.$ $C_{\mathrm{o}}$ ] vs. $t$, assuming $\Phi$ is equal to one (from unpublished data). The slope and the standard error of the slope were calculated via the LINEST function in Microsoft Excel.

\section{Sample Immersion Method}

\section{Sample Preparation}

From each bone section, 5-8 bone beams were machined (Fig. 1b), with dimensions of $3 \times 3 \times$ $30 \mathrm{~mm}$ each, using a custom jig designed for the Labcut 1010 Low Speed Diamond Saw. One end of the endosteal face of the bone was marked with a biocompatible paint (Bradley Products, Inc., Bloomington. MD). Bone beams were stored at $4{ }^{\circ} \mathrm{C}$ in $0.05 \%$ sodium azide (Sigma Aldrich) in PBS and tested within one month after preparation.

\section{Encapsulation of a Bone Beam}

Rectangular molds with inner dimensions of $32 \mathrm{~mm}$ (width) $\times 19 \mathrm{~mm}$ (depth) $\times 45 \mathrm{~mm}$ (length) and outer dimensions of $39 \mathrm{~mm}$ (width) $\times 27 \mathrm{~mm} \mathrm{(depth)} \times$ $52 \mathrm{~mm}$ (length) were constructed of silicone putty 


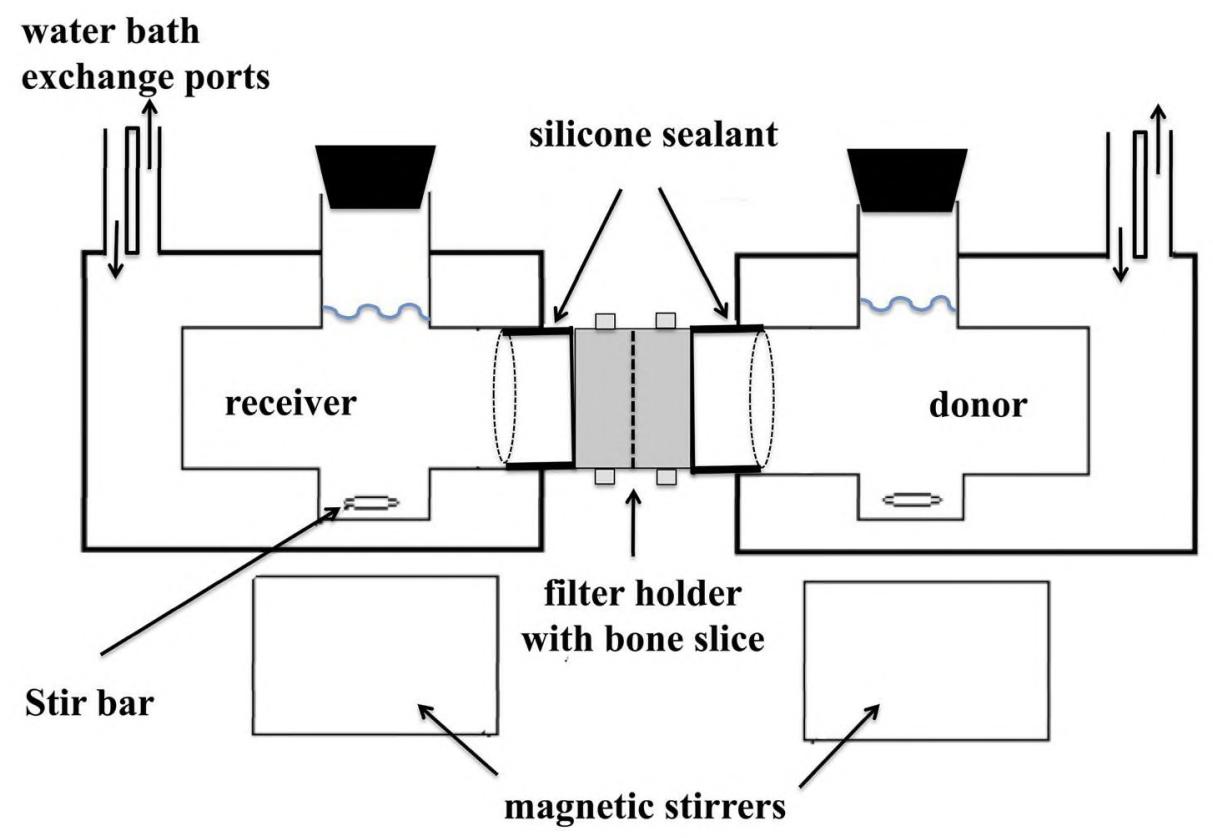

FIGURE 3. Experimental set-up for two-chamber diffusion apparatus. The two chambers are held tightly together by means of a clamp (not shown) across the outer walls of the two chambers. The two halves of the $25 \mathrm{~mm}$ filter holder (Advantec) are threaded together, with details of the bone sample held within this filter depicted in detail in Fig. 2. The outer surface of each half of the filter holder is glued to the inside of the plastic tube, each of which is then inserted snugly into the opening of the corresponding chamber, and sealed with silicone sealant. After clamping the two chambers together, silicone grease was applied around all interfaces to eliminate leaking. Rubber stoppers inserted into the chamber openings prevented evaporation.

(Easy Mold, CA). All surfaces of the bone beam were sealed with an orthodontic resin (Dentsply, Milford. $\mathrm{DE}$ ), which has been shown previously (data not shown) to effectively bond to the surface of bone and not leech into porous material. A $2.5 \mathrm{~mm}$ layer of orthodontic resin was first placed at the bottom of the mold. A period of $2 \mathrm{~min}$ allowed the resin to partially set, at which time a bone beam was positioned at the center of the mold and the periosteal surface lightly pressed into the resin. Resin was then applied over and around the beam until completely encapsulated, and allowed to set for $24 \mathrm{~h}$ at room temperature. After hardening, the encapsulated beam was removed from the mold, and the endosteal surface of the beam ( $30 \mathrm{~mm} \times 3 \mathrm{~mm}$ ) was exposed by cutting along the length of the beam with a diamond blade and saw (Buehler Isomet). To ensure that all of the dental resin was fully removed, the cut exposing the endosteal surface was made approximately $0.2 \mathrm{~mm}$ into the bone. The four exposed seams between the bone surface and the resin were sealed (Krazy Glue, Westerville, $\mathrm{OH}$ ) to prevent any fluid bypass around the tissue sample. After 5 min of drying, the sample was then placed in sterile PBS at $4{ }^{\circ} \mathrm{C}$ for $24 \mathrm{~h}$.

\section{Diffusion Experiment}

After $24 \mathrm{~h}$ in PBS, each beam was submerged in $50 \mathrm{~mL}$ of fluorescein sodium salt (Sigma-Aldrich) solution in PBS at a concentration of either 0.30 or $30 \mu \mathrm{M}$ (Fig. 1c), and incubated at $37^{\circ} \mathrm{C}$ for either 18 , 24 , or $30 \mathrm{~h}$. One beam from each of the 3 tibial sections was incubated for $18 \mathrm{~h}$ in PBS without fluorescein sodium salt as a control to determine background fluorescence under epifluorescent microscopy.

\section{Imaging}

After the specified incubation time, the samples were immediately prepared for epifluorescent microscopy imaging. From each beam, $2-6$ samples, each between 100 and 300 microns thick, were sliced perpendicular to the exposed surface from randomly selected positions within the central $20 \mathrm{~mm}$ of the beam (Figs. 1d, 1e) using the low-speed saw with a diamond blade. Each sample was glued (Krazy Glue) onto a microscope slide. The sample was coated with several drops of mounting media (H-1000 VectaShield Mounting Medium, Burlingame, CA) and covered with a cover slip. Numerous images (8-36) at an objective magnification of $10 \times$ were acquired for each of the samples using a fluorescent microscope (Olympus DP72, FITC filter, bin setting of $2 \times 2,25 \mathrm{~ms}$ exposure time, gain $=8$ ). Because of the varying sample thickness, refocusing was performed before each image capture. Images were montaged using Adobe Photoshop Elements (Adobe Systems Inc., San Jose, CA). Using Image Pro Plus (Media Cybernetics Inc., Rockville, MD), the montaged images were 
converted from color to grayscale using an 8.0 bit conversion. A bitmap analysis of the pixel intensity was obtained by sampling one out of 20 pixels, to reduce the execution time of the MATLAB (MathWorks, Natick. MA) program, yielding an image of roughly $100 \times 200$ pixels. Prior experiments confirmed that there was no significant difference in intensity profiles generated from the sampled image compared to the uncompressed image.

\section{Data Analysis}

Data analysis was performed using MATLAB custom-written code. The average intensity was calculated for images from the control sample to determine the level of background autofluorescence, which was subtracted from the intensities in all the test specimens. Each image array was divided into five regions and the average intensity was calculated within each region at each unit of distance $(0.012 \mathrm{~mm})$ from the exposed endosteal edge of the sample (Fig. 1f), to generate an intensity vs. distance plot (Fig. 5b).

The conservation of mass of the solute (fluorescein), assuming no reaction and one-dimensional transport by diffusion only, using Fick's Law of Diffusion, is described by:

$$
\frac{\partial C}{\partial t}=D \frac{\partial^{2} C}{\partial y^{2}}
$$

with the following initial and boundary conditions:

$$
\begin{gathered}
0 \leq y \leq L, t \leq 0, C=C_{\mathrm{o}} \\
y=0, t \geq 0, C=C_{\mathrm{s}} \\
y=L, t \geq 0, \frac{\partial C}{\partial y}=0
\end{gathered}
$$

where $C$ is the concentration of the solute (fluorescein) in the tissue, $C_{\mathrm{s}}$ is the solute concentration at the surface exposed to the solution, and $C_{\mathrm{o}}$ is the initial solute concentration in the tissue, with all concentrations assumed to be proportional to fluorescence intensity. The coordinate $y$ is the distance from the exposed face, $L$ is the total length of sample, $t$ is time, and $D$ is the effective diffusion coefficient of the solute in the tissue.

The solution to the one-dimensional diffusion equation, in finite medium, is given by ${ }^{31}$ :

$$
\begin{aligned}
\theta= & 1-2 \sum_{n=0}^{\infty}\left(\frac{(-1)^{n}}{\left(n+\frac{1}{2}\right) \pi} \cos \left[\left(n+\frac{1}{2}\right) \pi \eta\right]\right. \\
& \exp \left[-\left(n+\frac{1}{2}\right)^{2} \pi^{2} \tau\right)
\end{aligned}
$$

The dimensionless variables are defined as:

$$
\theta=\frac{C-C_{\mathrm{o}}}{C_{\mathrm{s}}-C_{\mathrm{o}}}, \quad \eta=\frac{y}{L}, \quad \tau=\frac{t D}{L^{2}}
$$

$C_{\mathrm{o}}$ was set to 0 since the autofluorescence value was previously subtracted from the measured intensities. The value of $C_{\mathrm{s}}$ was calculated from the average of the first five intensities. The intensity profile obtained for each region of each sample was fit to Eq. (6) by minimizing the sum of the squares of the error (SSE) in order to determine the value of the single parameter, the effective diffusivity.

\section{Samples and Statistical Analysis}

The sources of the tissue samples (i.e., left or right limb, position within the tibia) for each set of experiments are shown in Table 1. Diffusion data are reported as mean values $\pm \mathrm{SEM}$ in the figures. A students $t$ test was utilized to detect differences in the effective diffusion coefficients for comparison of the two diffusion techniques, the standard diffusion chamber vs. immersion technique (Fig. 6), and the effect of time on solute diffusion within a section (Fig. 7). The analysis of the variance (ANOVA) technique was used to detect differences between the diffusion coefficients based on sample section and varying solute concentration (Figs. 4a, 8). A two-way ANOVA was run to determine the effect of sample section, solute concentration and their possible interactions. To further isolate which group(s) differed from each other, a one-way ANOVA approach was employed with a post hoc multiple comparison test run when appropriate.

For all analyses run, results were considered statistically significant if $p<0.05$. Statistical analyses were all performed using Graphpad Prism v5.0 (GraphPad Software Inc., LaJolla, CA)

\section{RESULTS}

\section{Diffusion Chamber Results}

The radial diffusivity was measured using the diffusion chamber method on bone samples from the same tibia section at three concentrations of fluorescein $(0.3,30$, and $300 \mu \mathrm{M}$ ) (Fig. 4a). A decrease in effective diffusivity was observed with each increase in solute concentration, ranging from $1.6 \times 10^{-7} \pm$ $3.2 \times 10^{-8} \mathrm{~cm}^{2} / \mathrm{s}$ at $0.3 \mu \mathrm{M}$ to $1.4 \times 10^{-8} \pm 1.9 \times$ $10^{-9} \mathrm{~cm}^{2} / \mathrm{s}$ at $300 \mu \mathrm{M}$. This effect of solute concentration is significant between $0.3 \mu \mathrm{M}$ and $30 \mu \mathrm{M}$ $(p<.001)$. While significance is not achieved between $30 \mu \mathrm{M}$ and $300 \mu \mathrm{M}(p=0.176)$, likely due to the small sample size, the data displays a distinct trend of 
TABLE 1. Sources of bone tissue samples from the canine used in the two measurement techniques.

\begin{tabular}{|c|c|c|c|c|}
\hline \multirow[b]{2}{*}{ Anatomical location } & \multicolumn{2}{|c|}{ Method } & \multirow{2}{*}{$\begin{array}{l}\text { Number of samples } \\
\text { cut from each beam } \\
\text { for sample immersion } \\
\text { method, and solute } \\
\text { concentration }\end{array}$} & \multirow[b]{2}{*}{ Results } \\
\hline & $\begin{array}{l}\text { Diffusion } \\
\text { chamber }\end{array}$ & $\begin{array}{l}\text { Sample } \\
\text { immersion }\end{array}$ & & \\
\hline \multirow[t]{8}{*}{ Left midshaft, section 3} & $x$ & $x$ & $\begin{array}{l}\text { Diffusion chamber: } \\
\text { Bone Slice 1: }\end{array}$ & \\
\hline & & & 3 measurements $(0.3 \mu \mathrm{M})$ & Fig. 4 \\
\hline & & & 3 measurements $(30 \mu \mathrm{M})$ & Figs. 4,6 \\
\hline & & & 4 measurements $(300 \mu \mathrm{M})$ & Fig. 4 \\
\hline & & & Bone slice 2: & \\
\hline & & & 3 measurements $(30 \mu \mathrm{M})$ & Figs. 4,6 \\
\hline & & & Sample Immersion: & \\
\hline & & & $\begin{array}{l}\text { Beam 1:6 samples }(30 \mu \mathrm{M}) \\
\text { Beam 2:2 samples }(30 \mu \mathrm{M})\end{array}$ & $\begin{array}{l}\text { Fig. } 6 \\
\text { Fig. } 6\end{array}$ \\
\hline \multirow[t]{4}{*}{ Right proximal, section 2} & & $\mathrm{x}$ & Beam 1:5 samples $(0.3 \mu \mathrm{M})$ & Figs. 7,8 \\
\hline & & & Beam 2:2 samples $(0.3 \mu \mathrm{M})$ & Figs. 7,8 \\
\hline & & & Beam 3:2 samples $(30 \mu \mathrm{M})$ & Fig. 8 \\
\hline & & & Beam 4:5 samples $(30 \mu \mathrm{M})$ & Fig. 8 \\
\hline \multirow[t]{4}{*}{ Right midshaft, section 3} & & $\mathrm{x}$ & Beam 1:2 samples $(0.3 \mu \mathrm{M})$ & Figs. 7,8 \\
\hline & & & Beam 2:3 samples $(0.3 \mu \mathrm{M})$ & Figs. 7,8 \\
\hline & & & Beam 3:4 samples $(30 \mu \mathrm{M})$ & Figs. 5,8 \\
\hline & & & Beam 4:4 samples $(30 \mu \mathrm{M})$ & Fig. 8 \\
\hline \multirow[t]{2}{*}{ Right distal, section 4} & & $\mathrm{x}$ & Beam 1:2 samples $(0.3 \mu \mathrm{M})$ & Figs. 7,8 \\
\hline & & & Beam 2:2 samples $(30 \mu \mathrm{M})$ & Fig. 8 \\
\hline
\end{tabular}

decreasing diffusivity with increasing solute concentration. The diffusivity was linearly related to the logarithm of the solute concentration, as shown in Fig. 4b.

\section{Sample Immersion Results}

Detailed results are shown in Fig. 5 from one bone beam analyzed using the sample immersion method. Figure 5a demonstrates the intensity gradient in one sample of the beam that can be visualized after $24 \mathrm{~h}$ exposure to $30 \mu \mathrm{M}$ fluorescein. Pooling of the solute is clearly observed in several Haversian canals, which run perpendicular to the plane of the sample. The average intensity profile is shown for each region of the sample in Fig. 5a, along with the best-fit model result (Fig. 5b). The data for the 2 nd region were analyzed twice; first, using the data "as-is", i.e., including the intensity peak resulting from the Haversian canal; and second, filtering out the intensity peak, which resulted in $18 \%$ reduction in diffusivity (Fig. $5 \mathrm{c}$ ). In most of the samples, there is no discernable trend in the variation of diffusivities among the five regions (Fig. 5d), indicating a lack of edge effects from the resin coating at the top and bottom surfaces of the sample. The variation in values generally appears to be random, as expected from the heterogeneous nature of the tissue. An exception is sample 1, in which the diffusivities in the lower three regions of the sample were significantly lower than those in the first two regions (Fig. 5d).

\section{Comparison of Two Techniques}

Bone samples were obtained from section 3 (middiaphyseal region, Fig. 1a) of the left limb, for measurement using both the sample immersion and diffusion chamber methods (Table 1). The results in Fig. 6 show that there is not a significant difference in mean diffusivity obtained using the two measurement techniques on the same sample $\left(4.4 \times 10^{-8} \pm 1.1 \times\right.$ $10^{-8} \mathrm{~cm}^{2} / \mathrm{s}$ vs. $\left.3.3 \times 10^{-8} \pm 3.3 \times 10^{-9} \mathrm{~cm}^{2} / \mathrm{s}\right)$ thus validating the sample immersion technique.

\section{Effect of Incubation Time}

Diffusivity measurements were not significantly affected by the incubation times that were tested $(18 \mathrm{~h}$ and 30 h, Fig. 7), as expected, since time is accounted for explicitly in the model (Eq. 6). A middle incubation time of $24 \mathrm{~h}$ was then chosen for future experiments for convenience.

\section{Effect of Tissue Location}

Diffusivities were measured using the sample immersion technique using bone beams from Sects. 2 
(a)

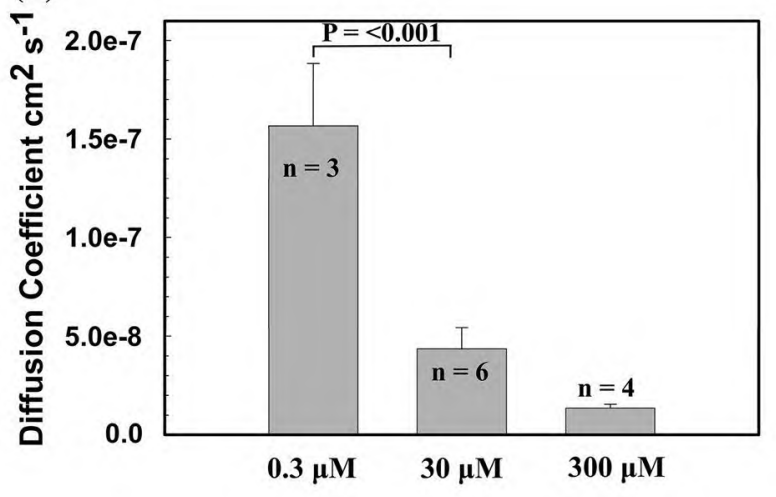

(b)

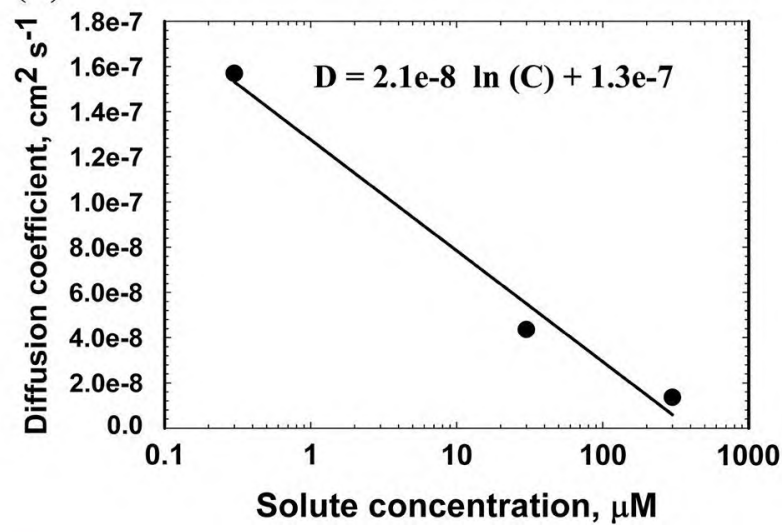

FIGURE 4. Diffusion coefficients measured using the twochamber diffusion system, at three different donor-cell concentrations of sodium fluorescein, using the same bone sample from the mid-diaphyseal region of the left tibia. (a) The number of measurements at each concentration is given by $n$; error bars represent standard error of the $\mathbf{n}$ measurements. 0.3 vs. $30 \mu \mathrm{M}$ concentrations were found to be significantly different $(p<.001)$; due to low sampling size, 30 vs. $300 \mu \mathrm{M}$ only approaches significance $(p=0.176)$. (b) The data from part $A$ on a semi-log plot, demonstrating that diffusivity is linearly related to the logarithm of the solute concentration.

(proximal), 3 (middle), and 4 (distal) portions of the tibial diaphysis (Fig. 1) at both 0.3 and $30 \mu \mathrm{M}$ fluorescein. The results in Fig. 8 indicate that there is not a significant variation in the measured diffusivity in the different regions of the bone. It should be noted that several of the raw data sets from section $4 \mathrm{dem}$ onstrated low intensities relative to the baseline and low signal/noise ratios, and thus these data sets could not be fit to the model equation, resulting in only 7 10 valid measurements at each solute concentration from this section. This indicates that the tissue in the distal section is significantly more heterogenous than the proximal or midshaft bone sections tested. In particular, while some distal samples demonstrated diffusivities similar to the values in the other sections of the tibia, other regions within the distal samples showed no solute diffusion, likely due to an absence of radial connectivity. Similar to the two-chamber method results shown in Fig. 4, higher solute concentrations resulted in significantly lower diffusivities for bone sections 2 and 3 (Fig. 8). Lastly, the mean diffusivity values in section 4 also demonstrated an inverse relationship between solute concentration and diffusivity; however, due to the larger variability in diffusivities in section 4 , including some outliers, the confidence level of this difference is only at $90 \%$ $(p=0.071)$.

Results were consistent between the left and right tibiae for corresponding sections and solute concentration. For example, the diffusivity of section 3 at $30 \mu \mathrm{M}$ is $3.3 \times 10^{-8} \pm 3.3 \times 10^{-9} \mathrm{~cm}^{2} / \mathrm{s} \quad(n=40)$ from the left tibia (Fig. 6), and $2.0 \times 10^{-8} \pm 2.8 \times 10^{-9} \mathrm{~cm}^{2} / \mathrm{s}$ $(n=40$ ) from the right tibia (Fig. 8), both using the sample immersion technique.

\section{DISCUSSION}

In this paper we report measurements of the effective diffusivity of fluorescein at the millimeter-scale in unloaded canine cortical bone tissue using two different techniques. The two-chamber diffusion system is a conventional method for measuring diffusivities in hydrogels and membranes. Solute concentrations in the receiver chamber were monitored over a $7-10$ day period, and the data fit to mathematical model of the system, based on material balance and Fick's Law of diffusion, to calculate the diffusivity. In the sample immersion method, a bone beam was immersed in the solution for a period of $18-30 \mathrm{~h}$, and then sectioned and imaged to obtain the solute concentration profile within the tissue, which was then analyzed using a model based on one-dimensional, unsteady state diffusion.

The similarities in both the average values and the variability between the two methods are remarkable, given that the sample immersion technique measures the effective diffusivities in the bone tissue from locations that are $2-5 \mathrm{~mm}$ apart, and the measurement variability that can arise from the microstructural variations in the bone across these distances. On the other hand, each diffusivity measurement using the diffusion chamber averages out these microstructural variations. A limitation of the results using the diffusion chamber method is the small sample number, since only three tissue samples could be obtained from each section of the tibia (Fig. 2b), although multiple measurements were made for each of these samples. Conversely, the sample immersion method allows for the acquisition of a much larger data set. An additional limitation is that all results presented here are from the tibiae harvested from a single canine. However, it is 
(c)

(a)

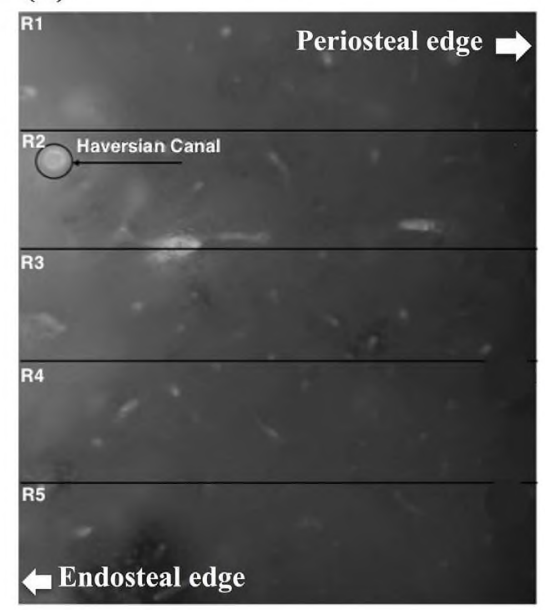

(b) 120

60

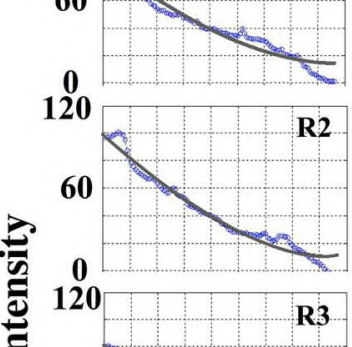

60

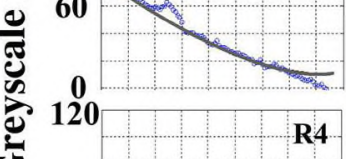

60

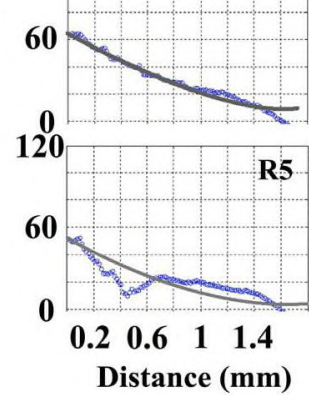

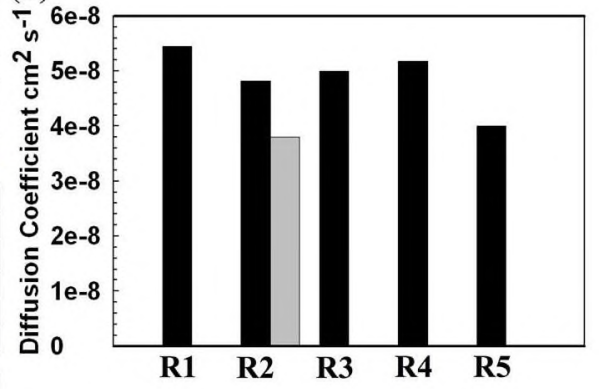

(d)
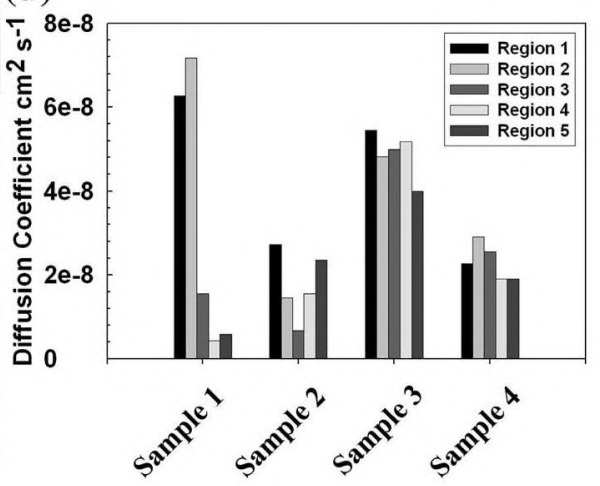

FIGURE 5. Sample results from a bone beam from the mid-diaphyseal region (section 3, as shown in Fig. 1) of the tibia. (a) A grayscale image from sample 3 from the bone beam, divided into five regions. Endosteal edge is at the left, periosteal edge at the right. (b) Average fluorescent intensities for each region, along with the best-fit model, from Eq. (6). (c) Diffusion coefficients for each region, obtained from the best-fit model. Data from region 2 was analyzed a 2 nd time (as shown in the light gray bar), with the intensity peak corresponding to the Haversian canal removed. (d) Diffusion coefficients for each of the five regions from four cross-sectional slices within one beam.

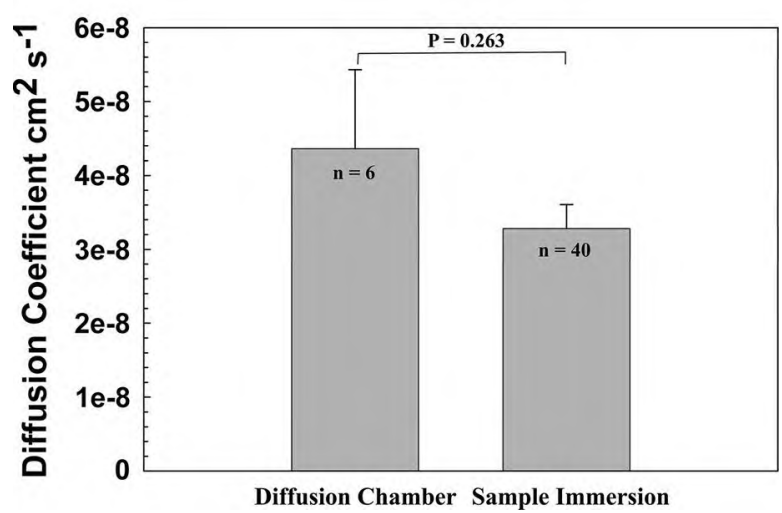

FIGURE 6. Measurements of bone samples from the same bone section (left limb, section 3 ) at $\mathbf{3 0} \mu \mathrm{M}$ fluorescein. The 40 measurements using the sample immersion technique were from 6 samples from beam \#1 and 2 samples from beam \#2, using $24 \mathrm{~h}$ incubation time. The 6 measurements using the diffusion chamber were from 2 slices, 3 measurements from each slice.

likely that these results can be generalized for other canine specimens, since previous work has reported similarities in tissue architecture and composition across a larger test pool of animals. ${ }^{22,32}$ Measurements

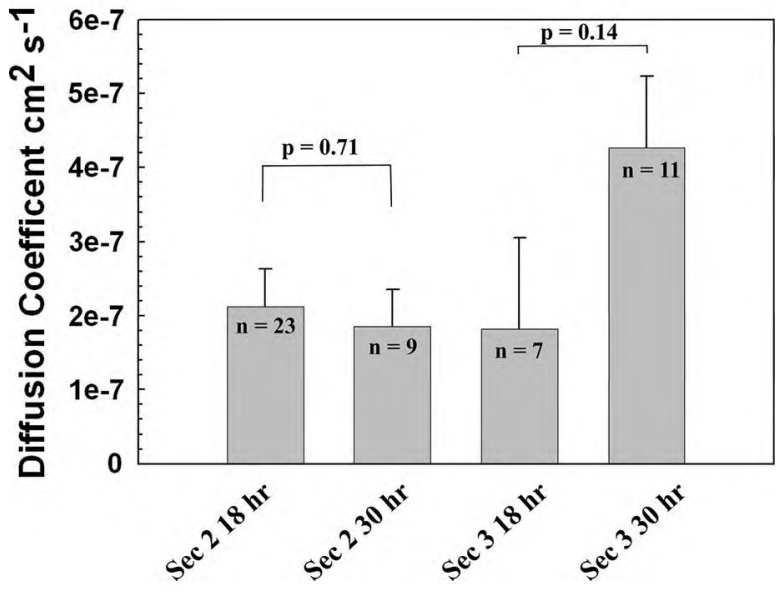

FIGURE 7. Diffusion measurements using sample immersion technique from sections 2 and 3 of bone (see Fig. 1) after 18 and $30 \mathrm{~h}$ of incubation. $p$ values are a result of 2 tailed unpaired calculations. Bars indicate standard error, $n$ indicates number of region measurements at each condition. Fluorescein concentration is $0.30 \mu \mathrm{M}$.

of bone permeability and porosity also showed low variability over multiple canine measurements. ${ }^{36}$

The effective diffusivity measurements from the literature vary over four orders-of-magnitude, even for 


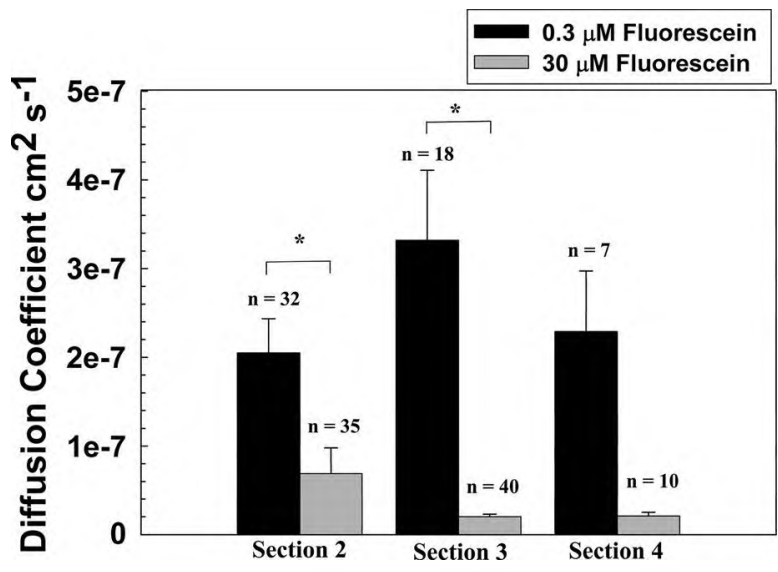

FIGURE 8. Diffusivity measurements using sample immersion technique; section numbers refer to section of the tibia (Fig. 1), all from right limb. Values at $0.3 \mu \mathrm{M}$ are from the combination of results at 18 and $30 \mathrm{~h}$ exposure time from Fig. 7; values at $30 \mu \mathrm{M}$ are from $24 \mathrm{~h}$ exposure time. $n$ is the number of samples measured. *indicates $p<0.05$. The variation among section numbers was not significant $(p>0.05)$, at both $0.3 \mu \mathrm{M}$ and $30 \mu \mathrm{M}$ fluorescein.

similar compounds within cortical bone tissue, because of the scale of analysis and heterogeneity of the tissue, and differences in tissue structure among different mammalian organisms, ranging from $7 \times 10^{-10} \mathrm{~cm}^{2} / \mathrm{s}$ for diffusion of a $300 \mathrm{Da}$ dye within the dense bone matrix, ${ }^{24}$ to $3 \times 10^{-6} \mathrm{~cm}^{2} / \mathrm{s}$ for diffusion of fluorescein sodium salt $(376 \mathrm{Da})$ in an individual mouse osteocytic lacunar-canalicular system. ${ }^{19.34}$ Not surprisingly, our measurements of fluorescein diffusivity at the macrolevel of the canine cortical tissue fall midway between these two extremes, at $2-3 \times 10^{-8} \mathrm{~cm}^{2} / \mathrm{s}$ (Fig. 6). We would expect similar diffusivities in human cortical bone tissue, given the similarity of the tissue structure in the two organisms. ${ }^{2,10}$ Tissue heterogeneity, even within a single animal, also accounts for some of the variation in reported values. As shown in Fig. 5, even regions of cortical bone within a few millimeters distance from one another can yield effective diffusivity values that vary over a three-fold range. And as reported here, the solute concentration has a significant effect on the diffusivity, and thus reported diffusivity values must be interpreted in the context of the specific experimental conditions under which they were measured.

The diffusivity values reported here depend on the accuracy of the models in representing diffusion in the two measurement approaches. The two-chamber diffusion system model (Eqs. (1)-(3)) relies on an assumption of quasi-steady state within the sample, which given the small sample thickness (about $0.5 \mathrm{~mm}$ ), is very reasonable. Care was also taken to eliminate any fluid bypass around the sample by sealing the interface between the sample and the resin in the holder. Equation (6) assumes that the transport in the sample immersion method is one-dimensional in a beam of finite length, and thus the calculations here also rely on elimination of fluid bypass between the sample and the resin. Both methods of analysis neglect potential adsorption of the solute to pore surfaces, and interactions of the ionic forms of the solute with the tissue matrix, which likely exists in vivo for physiologically relevant molecules. In fact, numerical investigations have shown that these electrostatic interactions within the lacunae-canalicular network may have a greater effect in driving transport in unloaded bone tissue than pure concentration-driven diffusion. ${ }^{18}$ The saline concentration of the PBS solution used to bathe the tissue is also expected to affect the transport rate. ${ }^{18}$ Thus, the concentration profiles generated experimentally in this work likely represent the result of both of these transport mechanisms, and the calculated diffusivities may actually underestimate the true diffusivity of the fluorescein anion.

An interesting result observed here is the inverse relationship between solute concentration and the measured diffusivity, which is clearly significant between 0.3 and $30 \mu \mathrm{M}$, as measured with both technqiues (Figs. 4, 8). There are very few reports in the literature of this phenomenon in biological applications and none found using bone as the porous media. Albro et al. observed that the diffusivity of fluoresceinconjugated dextran $(70 \mathrm{kDa})$ in agarose hydrogels, as measured using FRAP, decreased $90 \%$ as the solute concentration increased almost three orders of magnitude, from $7 \mu \mathrm{m}$ to $3 \mathrm{mM}^{1}{ }^{1}$ Diffusivities of proteins have shown both positive and negative relationships with concentration, attributed to surface charge interactions. ${ }^{11}$ The relationship between diffusivity and solute concentration has been attributed to the nonideal solution behavior, as represented by ${ }^{7}$ :

$$
D=D_{\mathrm{o}}\left(1+\frac{\partial \ln \gamma}{\partial \ln C}\right)
$$

where $\gamma$ is the activity coefficient of the solute, $C$ is the solute concentration, and $D_{\mathrm{o}}$ is the diffusivity at infinite dilution. For non-ideal solutions, the activity coefficient can vary nonlinearly and as a non-monotonic function of $C$, causing the diffusivity to either increase or decrease with solute concentration. Given the monotonic, negative relationship between diffusivity and concentration reported here, Eq. (8) indicates that $\partial \ln \gamma / \partial \ln C$ is negative and decreases with concentration, and thus the activity coefficient also decreases with solute concentration.

Fluorescein's chemical structure shares some similarities with vitamin $\mathrm{D}$, testosterone, and estrogen (all derived from cholesterol precursors). ${ }^{5.12}$ It can be argued that the transport of fluorescein in osteonal 
bone should model that of these important molecules affecting bone metabolism. The blood-circulating form of vitamin D (25-hydroxy vitamin D), with a molecular weight of $385 \mathrm{Da}$ (compared to $376 \mathrm{Da}$ for fluorescein), has a physiological concentration of $0.095 \mu \mathrm{M} .{ }^{12}$ The model equation shown in Fig. 4 can be used to estimate the diffusivity of vitamin $\mathrm{D}\left(1.8 \times 10^{-7} \mathrm{~cm}^{2}\right)$ s) at this concentration, given that the vitamin $\mathrm{D}$ concentration is below the minimum concentration examined here $(0.3 \mu \mathrm{M})$. The amount of time $(t)$ that it takes a molecule to diffuse a distance $x$, is given by Einstein's equation:

$$
t \approx \frac{x^{2}}{2 D}
$$

Using the estimated diffusivity for vitamin D given above, and the maximum distance between a Haversian canal and an osteocyte, estimated at $100 \mu \mathrm{m},{ }^{29}$ the maximum time required for vitamin $\mathrm{D}$ to travel from a blood source to the farthest osteocyte is $5 \mathrm{~min}$. The active form of Vitamin $\mathrm{D}$ on bone tissue is 1,25 dihydroxy vitamin $\mathrm{D}$, which has pronounced transient behavior, with peak concentrations in the $\mathrm{nM}$ range for short periods of time. Given the inverse relationship between solute concentration and diffusivity, it is expected that the diffusivity of the bioactive 1,25 dihydroxy vitamin $\mathrm{D}$ will be higher than the value shown above, resulting in a transport time even less than $5 \mathrm{~min}$. This short transport time indicates that mechanical loading will likely have little effect on vitamin D distribution within the tissue and that the embedded osteocytes and surface osteoblasts will experience similar concentrations of vitamin $\mathrm{D}$.

Many of the important signaling molecules in bone are much larger than fluorescein and vitamin $\mathrm{D}$, such as insulin (5800 Da) and parathyroid hormone (PTH; $9400 \mathrm{Da})$ and its related protein homolog PTHrP $(-20,000 \mathrm{Da}){ }^{13,20,27}$ From the Stokes-Einstein equation for liquid diffusion coefficients, ${ }^{7}$ we see that diffusivity is inversely proportional to solute radius:

$$
D=\frac{k_{\mathrm{B}} T}{6 \pi \mu R}
$$

where $k_{\mathbf{B}}$ is Boltzmann's constant, $T$ is temperature, $\mu$ is solvent viscosity, and $R$ is solute radius. Given approximate radii of monomeric insulin $(1.2 \mathrm{~nm})^{23}$ and sodium fluorescein $(0.45 \mathrm{~nm}),{ }^{21}$ then the diffusivity of insulin in this tissue can be estimated from this ratio, multiplied by diffusivity of fluorescein $\left(2.6 \times 10^{-8}\right.$ $\mathrm{cm}^{2} / \mathrm{s}$, Fig. 6), to yield a diffusivity of $1 \times 10^{-8} \mathrm{~cm}^{2} / \mathrm{s}$, and a transport time of $83 \mathrm{~min}$, according to Eq. (9). Also, given the similar size, we would expect that the teriparitide form of PTH (4500 Da) to exhibit similar diffusivity as that calculated for insulin above. By comparison, similar calculations using PTHrP with radius estimated at $1.9 \mathrm{~nm}$, yields a diffusivity of $6 \times 10^{-9} \mathrm{~cm}^{2} / \mathrm{s}$, and a transport time of $139 \mathrm{~min}$. In the absence of mechanical loading, this calculated lower diffusivity and longer transport time would suggest that an osteocyte embedded in an osteon may experience a much different concentration of PTHrP (or full length $\mathrm{PTH}$ ) as opposed to the teriparitide form of PTH than does a surface osteoblast. Substantially longer diffusion times for larger bone signaling proteins such as PTHrP or bone morphogenic proteins $(25-30 \mathrm{kDa}$ dimers) would imply that in a microgravity environment, or in extended periods of bed rest in which there is no loading on the lower limbs, the osteocytes embedded within the cortical tissue would experience much lower concentrations of these growth factors compared to osteoblasts at the surface. In summary, our analysis, based on a classical diffusive mechanism, gives a long transit time for large signaling molecules through the bone tissue, as has been discussed previously. ${ }^{19}$ The measurement of loadinduced transport rates can be readily accommodated by the novel immersion technique presented here.

\section{ACKNOWLEDGMENTS}

The assistance of Dr. Xiang Zhou, Department of Chemistry at CSU, with use of the spectrofluorometer, is gratefully acknowledged. Funds were provided by the Faculty Research and Development Program and the Undergraduate Summer Research Program at CSU.

\section{REFERENCES}

\footnotetext{
${ }^{\mathrm{I}}$ Albro, M. B., V. Rajan, R. Li, C. T. Hung, and G. A. Ateshian. Characterization of the concentration-dependence of solute diffusivity and partitioning in a model dextran-agarose transport system. Cell Mol. Bioeng. 2: 295-305, 2009.

${ }^{2}$ An, Y. H., and R. J. Freidman. Animal Models in Orthopaedic Research. Boca Raton, FL: CRC Press, 1998, 624 pp.

${ }^{3}$ Androjna, C., J. E. Gatica, J. M. Belovich, and K. A. Derwin. Oxygen diffusion through natural extracellular matrices: implications for estimating "critical thickness" values in tendon tissue engineering. Tissue Eng. Part A 14:559-569, 2008.

${ }^{4}$ Cardoso, L., S. P. Fritton, G. Gailani, M. Benalla, and S. C. Cowin. Advances in assessment of bone porosity, permeability and interstitial fluid flow. J. Biomech. 46:22532265, 2013.
} 
${ }^{5}$ Champe, P. C., R. A. Harvey, and D. R. Ferrier. Biochemistry, 3rd edn. Baltimore: Lippincott, 2005, pp. 235-238.

${ }^{6}$ Ciani, C., D. Sharma, S. B. Doty, and S. P. Fritton. Ovariectomy enhances mechanical load-induced solute transport around osteocytes in rat cancellous bone. Bone 59:229-234, 2014.

${ }^{7}$ Cussler, E. L. Diffusion: Mass Transfer in Fluid Systems. Cambridge: Cambridge University Press, p. 647, 2009.

${ }^{8}$ Dirksen, T. R., and G. V. Marinetti. Lipids of bovine enamel and dentin and human bone. Tissue Res. 6:1-10, 1970.

${ }^{9}$ Eriksen, E. F. Cellular mechanisms of bone remodeling. Rev. Endocr. Metab. Disord. 11:219-227, 2010.

${ }^{10}$ Fernandez-Seara, M. A., S. L. Wehrli, and F. W. Wehrli. Diffusion of exchangeable water in cortical bone studied by nuclear magnetic resonance. Biophys. J. 82:522-529, 2002.

${ }^{\mathrm{H}}$ Geankoplis, C. Transport Processes and Separation Process Principles (Includes Unit Operations). Upper Saddle River NJ: Prentice Hall Press, 2003; (1056 pp).

${ }^{12}$ Hollis, A. Vitamin D: Synthesis, Metabolism, and Clinical Measurement. Disorders of Bone and Mineral Metabolism. Philadelphia: Lippincott Williams and Wilkins, 2002, 159 pp.

${ }^{13}$ Jilka, R. L. Molecular and cellular mechanisms of the anabolic effect of intermittent PTH. Bone 40:1434-1446, 2007.

${ }^{14}$ Knothe Tate, M. L., P. Niederer, and U. Knothe. In vivo tracer transport through the lacunocanalicular system of rat bone in an environment devoid of mechanical loading. Bone 22:107-117, 1998.

${ }^{15}$ Knothe Tate, M. L., and U. Knothe. An ex vivo model to study transport processes and fluid flow in loaded bone. J. Biomech. 33:247-254, 2000.

${ }^{16}$ Knothe Tate, M. L., U. Knothe, and P. Niederer. Experimental elucidation of mechanical load-induced fluid flow and its potential role in bone metabolism and functional adaptation. Am. J. Med. Sci. 316:189-195, 1998.

${ }^{17}$ Lang, S. B., N. Stipanich, and E. A. Soremi. Diffusion of glucose in stressed and unstressed canine femur in vitro. Ann. N. Y. Acad. Sci. 238:139-148, 1974.

${ }^{18}$ Lemaire, T., J. Kaiser, S. Naili, and V. Sansalone. Textural versus electrostatic exclusion-enrichment effects in the effective chemical transport within the cortical bone: a numerical investigation. Int. J. Numer. Methods Biomed. Eng. 11:1223-1242, 2013.

${ }^{19} \mathrm{Li}$, W., L. You, M. B. Schaffler, and L. Wang. The dependency of solute diffusion on molecular weight and shape in intact bone. Bone 45:1017-1023, 2009.

${ }^{211}$ McCauley, L. K., and T. J. Martin. Twenty-five years of PTHrP progress: from cancer hormone to multifunctional cytokine. J. Bone Miner. Res. 27:1231-1239, 2012.

${ }^{21}$ Montermini, D., C. P. Winlove, and C. Michel. Effects of perfusion rate on permeability of frog and rat mesenteric microvessels to sodium fluorescein. J. Physiol. 543:959-975, 2003.
${ }^{22}$ Morris, M. A., J. A. Lopez-Curto, S. P. Hughes, K. N. An, J. B. Bassingthwaighte, and P. J. Kelly. Fluid spaces in canine bone and marrow. Microvasc. Res. 2:188-200, 1982.

${ }^{23}$ Oliva, A., J. Farina, and M. Llabres. Development of two high-performance liquid chromatographic methods for the analysis and characterization of insulin and its degradation products in pharmaceutical preparations. J. Chromatogr. $B$ Biomed. Sci. Appl. 749:25-34, 2000.

${ }^{24}$ Patel, R. B., J. M. O'Leary, S. J. Bhatt, A. Vasnja, and M. L. Knothe Tate. Determining the permeability of cortical bone at multiple length scales using fluorescence recovery after photobleaching techniques. Proceedings of the 51st Annual Meeting of the Orthopaedic Research Society, Washington D.C., 2004.

${ }^{25}$ Piekarski, K., and M. Munro. Transport mechanism operating between blood supply and osteocytes in long bones. Nature 269:80 82, 1977.

${ }^{26}$ Pietrzak, W. S., and J. Woodell-May. The composition of human cortical allograft bone derived from FDA/AATBscreened donors. J. Craniofac. Surg. 16:579-585, 2005.

${ }^{27}$ Potts, J. T. Parathyroid hormone: past and present. J. Endocrinol. 187:311-325, 2005.

${ }^{28}$ Price, C., X. Zhou, W. Li, and L. Wang. Real-time measurement of solute transport within the lacunar-canalicular system of mechanically loaded bone: direct evidence for load-induced fluid flow. J. Bone Miner. Res. 26:277-285, 2011.

${ }^{29}$ Qui, S., D. P. Fyhrie, S. Palnitkar, and D. S. Rao. Histomorphometric assessment of haversian canal and osteocyte lacunae in different-sized osteons in human rib. Anat. Rec. 272A:520-525, 2003.

${ }^{30}$ Schaffler, M. B., and D. B. Burr. Stiffness of compact bone: effects of porosity and density. J. Biomech. 21:13-16, 1988.

${ }^{31}$ Truskey, G. A., F. Yuan, and D. F. Katz. Transport Phenomena in Biological Systems. Upper Saddle River, NJ: Pearson/Prentice Hall, 2004; (888 pp).

${ }^{32}$ Wang, X., J. D. Mabrey, and C. M. Agrawal. An interspecies comparsion of bone fracture properties. Bio-Med. Mater. Eng. 8:1-9, 1998.

${ }^{33}$ Wang, X., and Q. Ni. Determination of cortical bone porosity and pore size distribution using a low field pulsed NMR approach. J. Orthop. Res. 21:312-319, 2009.

${ }^{34}$ Wang, L., Y. Wang, Y. Han, S. C. Henderson, R. J. Majeska, S. Weinbaum, and M. B. Schaffler. In situ measurement of solute transport in the bone lacunar-canalicular system. Proc. Natl Acad. Sci. U.S.A. 102:11911-11916, 2005. ${ }^{35}$ Wang, X. Fundamental biomechanics in bone tissue engineering. In: Synthesis Lectures on Tissue Engineering. San Rafael, CA: Morgan \& Claypool Publishers, 2010, 225 pp.

${ }^{36}$ Wen, D., C. Androjna, A. Vasanji, J. Belovich, and R. J. Midura. Lipids and collagen matrix restrict the hydraulic permeability within the porous compartment of adult cortical bone. Ann. Biomed. Eng. 3:558-569, 2010.

${ }^{37}$ Yang, S., K. F. Leong, Z. Du, and C. K. Chua. The design of scaffolds for use in tissue engineering. Part II. Rapid prototyping techniques. Tissue Eng. 8:1-11, 2002. 